\title{
The ubiquitous role of Smartphones in mobile health
}

\begin{abstract}
Emerging technological advances are not only revolutionizing smartphones, but are changing how healthcare is utilized in the United States in conjunction with this mobile technology. Smartphones and their associated devices are now used to process data from a myriad of sources, including mobile health applications, wireless databases and networks, extension and adaptation devices, and patient tracking or monitoring systems. With a wide variety of health data available, data monitoring, collection, and transmission, via mobile technology is being integrated into many healthcare models. This paper reviews the advances in smartphone applications, medical adapters and extension devices that are now available to users, patients and providers alike, and the impact that this access currently has and will continue to have in the healthcare field. We sought to identify smartphone adapters and medical devices that are now smartphone-compatible, and to highlight the implications of their use and implementation in patient care. With a focus on identifying the challenges that this technology currently faces and will continue to encounter, we aim to identify further areas of potential innovation and improvement. Smartphones are shaping the future of medicine and staying at the forefront of these innovations will allow for a better collaboration between healthcare providers and patients in order to provide individualized and high quality care.
\end{abstract}

Keywords: mobile phone, mobile health, telemedicine, telehealth, eHealth, connected device, quantified self
Volume I Issue I - 20I4

\author{
Elvis Camacho,' Melissa LoPresti,' Geoff \\ Appelboom,' Emmanuel LP Dumont, ${ }^{2}$ Blake \\ Taylor,' E Sander Connolly' \\ 'Department of Neurosurgery, Columbia University, USA \\ ${ }^{2}$ The Joan and Irwin Jacobs Technion-Cornell Innovation \\ Institute, USA
}

\begin{abstract}
Correspondence: Geoff Appelboom, Department of Neurosurgery, Columbia University College of Physicians and Surgeons, 630 West 168th Street, P\&S 5-454, New York, NY 10032, USA, Tel 212-305-4679, Email ejc2163@columbia.edu
\end{abstract}

Received: August 19, 2014 | Published: September 27, 2014
Abbreviations: mHealth, mobile health; PAN, personal area network; WBAN, wireless body area network; PPACA, patient and protection affordable care act

\section{Introduction}

As utilization of technology expands in healthcare, development of new wireless health monitoring devices and mobile applications challenge the standard of care. ${ }^{1}$ The use of mobile devices in medical practice, via tablets and smartphones, is commonly referred to as mobile health (mHealth) and is part of a larger application of wireless technology defined in telehealth. ${ }^{2}$ This emerging field is of growing interest due to increasing access to smartphones, ${ }^{3}$ high-performance technology that demonstrates promising potential in healthcare, and the potential to augment the patient's role in the management of their health. Recent estimates suggest that, by 2015, mobile health applications will reach over 500million smartphone users, growing to $50 \%$ of all users by $2018 .{ }^{4}$ Smartphones are the most common personalized computer, ${ }^{5}$ with estimates of over 40,000 mobile health applications with upwards of 250,000 individuals having downloaded at least one application. ${ }^{4}$ The growth of the smartphone industry is occurring rapidly and the amount of innovations and usage of these devices is limitless.

Many new smartphone innovations optimize their clinical utility, providing improved connectivity to $4 \mathrm{G}$ networks that provide fast and reliable internet connections, coming equipped with a variety of sensors (accelerometer, barometer, digital compass, GPS, gyroscope, heart rate monitor, and thermometer), having large storage capacities, and coming preloaded with various health applications that can used to track workouts, calories burned, weight, and environmental factors. ${ }^{6}$ These personal computers are virtually always on and at hand and are capable of a variety of functions, ${ }^{7}$ making them widely available for everyday personal use or clinically-based interventions.
Coupling these technological strides with their ubiquity in society, it is no wonder that smartphones hold quite a role in healthcare. With the potential of this technology, and the current strides being made in the field of mobile health, we aim to review the current state of the field, summarizing the existing technology, identifying what obstacles and limitations exist, and projecting what future innovations may develop.

\section{Current status of technology}

\section{Smartphones in healthcare}

Patients are the most underutilized resource in health care ${ }^{8}$ and with the current shift towards mHealth there is a growing use in this untapped resource. The increased connectivity between patients and clinicians from the usage of smartphones yields a better exchange and communication of information while promoting patient engagement. This model places more emphasis on patient involvement by allowing them to self-monitor remotely rather than being monitored by clinicians in a medical setting. Providing patients an active, rather than passive, role in their own healthcare management facilitates empowerment. An example of this was displayed by Burke et al, during a 24-month randomized clinical trial where they demonstrated that the use of mobile devices in overweight and obese patients increased patient adherence to dietary self-monitoring, consequently leading to better health outcomes. ${ }^{8,9}$ While it is unclear how much of this can be attributed to the concept that simply monitoring individuals can improve compliance,${ }^{10}$ the use of this technology in self-monitoring, motivation, and patient empowerment is strong. Not only is there benefit to the patient, but the integration of smartphones in medicine can greatly improve information accessibility both as well as reduce the likelihood of errors in clinical treatment. ${ }^{11,12}$ The potential use of smartphones in mHealth, coupled with user demand, both clinician and non-clinician, will propel smartphones to the forefront as a quintessential health care device. 
The role of medical devices: Smartphone innovations are revolutionizing healthcare in the United States, perhaps most recently exemplified by the Russell et al., ${ }^{13}$ study, which established the effectiveness of glycemic control in Type 1 Diabetics using a smartphone-controlled bionic pancreas. Their results not only showed improved glycemic control in patients, but demonstrated an innovative use of smartphones. The ability of smartphones to process data from myriad sources allows them to be integrated into medical devices and healthcare models. This is exemplified by the recent partnership between Mayo Clinic, Apple, and Health kit to be able to collect, store and present health information with medical applications.${ }^{14}$ Coupled with enhanced technology, many applications are further expanding on the role of smartphones as a medical device and/or extension devices and adapters have been crafted to provide users with a wider array of uses for their smartphone.

Biotechnology companies have worked with several smartphone platforms to create biosensors, and have adapted technologies to improve compatibility with wireless devices and mobile applications to expand access and utility. The constant connectivity of smartphones gives users the ability to monitor their health in various settings, with continuous real-time, on-demand access to hundreds of variables regardless of time and place ${ }^{6}$. The use of this longitudinal data, such as blood pressure, blood glucose and heart rate and rhythms, can provide more accurate information to patients and clinicians to tailor the management of their health, addressing individual needs and improving the efficiency of how medicine is practiced.

Table 1 identifies many of these recent technological advances in smartphone devices and application extensions which are now accessible, including blood pressure cuffs, glucose meters and telemetry monitors. ${ }^{15-20}$ These devices are made to be easy to use and many of them are wirelessly controlled via smartphone applications. As with the wireless blood pressure cuff, the user simply puts on the cuff and operates the device through the smartphone commands. ${ }^{16}$ Once a device has taken the users information, it will be presented onto the smartphone display to either store or share with a clinician. ${ }^{19}$ Other devices incorporate sensors into smartphones accessories, such as the smartphone case electrocardiogram. ${ }^{19}$ This allows the user to provide more objective diagnostic tools for their clinician from remote environments. These showcases how smartphone extensions are being created that enhance the phone's capabilities as portable medical equipment. ${ }^{21-26}$ Some of these devices amplify the magnification of the smartphone to be used in diagnoses or use the smartphone to process and interpret information from imaging devices, such as the ophthalmoscope or ultrasound extension. There are also hand-held devices that can use biological specimens to perform hematologic assays ${ }^{25}$ including one prototype that uses a small credit cardsized cartridge to collect the specimen, which is then placed onto a hand-held biosensor for analysis. This system operates through a smartphone application and reduces the cost and time to less than ten dollars and twenty minutes, per assay.

Table I Innovations in mHealth devices and Smartphone application extensions

\begin{tabular}{|c|c|c|c|c|}
\hline $\begin{array}{l}\text { Device or } \\
\text { application } \\
\text { extension }\end{array}$ & Year & Companies & Purpose & $\begin{array}{l}\text { Conditions/disease for } \\
\text { which devices may be } \\
\text { used }\end{array}$ \\
\hline Blood pressure cuff & 2012 & $\begin{array}{l}\text { Withings (Boston, MA, USA) } \\
\text { iHealth Lab (Mountain View, } \\
\text { CA, USA) }\end{array}$ & $\begin{array}{l}\text { Allows for remote measuring, recording, and } \\
\text { transmission of blood pressure }\end{array}$ & $\begin{array}{l}\text { Cardiovascular Diseases } \\
\text { Hypertension } \\
\text { Primary Care }\end{array}$ \\
\hline $\begin{array}{l}\text { Blood glucose } \\
\text { meter and diabetes } \\
\text { management } \\
\text { applications }\end{array}$ & 2011 & $\begin{array}{l}\text { Sanofi Aventis (Bridgewater, NJ, } \\
\text { USA) }{ }^{18}\end{array}$ & $\begin{array}{l}\text { Allows for remote measuring, recording, } \\
\text { and transmission of blood glucose level, } \\
\text { carbohydrate intake, and/or insulin doses }\end{array}$ & $\begin{array}{l}\text { Diabetes Mellitus } \\
\text { Primary Care }\end{array}$ \\
\hline $\begin{array}{l}\text { Heart rate and } \\
\text { rhythm Smartphone } \\
\text { case }\end{array}$ & 2012 & iHealth Lab ${ }^{17}$ & $\begin{array}{l}\text { Allows for continuous monitoring, recording, } \\
\text { and transmission of heart rate and rhythm }\end{array}$ & $\begin{array}{l}\text { Arrhythmias } \\
\text { Cardiovascular Diseases } \\
\text { Primary Care }\end{array}$ \\
\hline $\begin{array}{l}\text { Electro- } \\
\text { encephalography } \\
\text { adapter }\end{array}$ & 2014 & $\begin{array}{l}\text { AliveCor (San Francisco, CA, } \\
\text { USA) }{ }^{19}\end{array}$ & $\begin{array}{l}\text { Allows for portable Electro-encephalography } \\
\text { monitoring and data transmission }\end{array}$ & $\begin{array}{l}\text { Epilepsy } \\
\text { Neurological Diseases } \\
\text { Seizure Disorders }\end{array}$ \\
\hline Otoscope adapter & 2012 & $\begin{array}{l}\text { Technical University of } \\
\text { Denmark (Kongens Lyngby, } \\
\text { Denmark) }\end{array}$ & $\begin{array}{l}\text { Allows for visualization of external acoustic } \\
\text { meatus and tympanic membrane }\end{array}$ & $\begin{array}{l}\text { Infectious Diseases } \\
\text { Otologic Diseases } \\
\text { Pediatric Care } \\
\text { Primary Care }\end{array}$ \\
\hline $\begin{array}{l}\text { Ophthalmoscope } \\
\text { device }\end{array}$ & 2014 & $\begin{array}{l}\text { Cellscope (San Francisco, CA, } \\
\text { USA) }{ }^{21}\end{array}$ & $\begin{array}{l}\text { Allows for visualization of internal eye } \\
\text { structures }\end{array}$ & $\begin{array}{l}\text { Cardiovascular Diseases } \\
\text { Neurological Diseases } \\
\text { Ophthalmologic Diseases } \\
\text { Primary Care }\end{array}$ \\
\hline $\begin{array}{l}\text { Hand-held } \\
\text { microscope } \\
\text { smartphone adapter }\end{array}$ & 2012 & Skylight (Oakland & $\begin{array}{l}\text { Allows for remote microscopic examination of } \\
\text { specimens from patients }\end{array}$ & $\begin{array}{l}\text { Dermatologic Diseases } \\
\text { Hematologic Diseases } \\
\text { Infectious Diseases }\end{array}$ \\
\hline
\end{tabular}




\begin{tabular}{|c|c|c|c|c|}
\hline $\begin{array}{l}\text { Device or } \\
\text { application } \\
\text { extension }\end{array}$ & Year & Companies & Purpose & $\begin{array}{l}\text { Conditions/disease for } \\
\text { which devices may be } \\
\text { used }\end{array}$ \\
\hline $\begin{array}{l}\text { Smartphone } \\
\text { ultrasound imaging } \\
\text { system }\end{array}$ & 2011 & MobiSante (Redmond & Allows for portable use of ultrasound imaging & $\begin{array}{l}\text { Cardiovascular Diseases } \\
\text { Emergency Medicine } \\
\text { EndocrinologicDisease } \\
\text { Gastrointestinal Disease } \\
\text { Musculoskeletal Diseases } \\
\text { Obstetrics and Gynecology } \\
\text { Pediatric Care } \\
\text { Primary Care } \\
\text { Reproductive Health } \\
\text { Urological Diseases }\end{array}$ \\
\hline & 2011 & $\begin{array}{l}\text { University of Rhode Island } \\
\text { (Kingston }\end{array}$ & $\begin{array}{l}\text { Allows portable measurement of laboratory } \\
\text { values in patient blood samples }\end{array}$ & $\begin{array}{l}\text { Cardiovascular Disease } \\
\text { Endocrinologic Disease } \\
\text { Gastrointestinal Disease } \\
\text { Hematologic Disease } \\
\text { Infectious Disease } \\
\text { Nephrological Disease }\end{array}$ \\
\hline $\begin{array}{l}\text { Wireless laboratory } \\
\text { hand-held sensor }\end{array}$ & 2015 & Cue (San Diego & $\begin{array}{l}\text { Allows portable measurement of laboratory } \\
\text { values in patient samples and specimens, and } \\
\text { provides advice and interpretation of results. }\end{array}$ & $\begin{array}{l}\text { Cardiovascular Disease } \\
\text { Endocrinologic Disease } \\
\text { Gastrointestinal Disease } \\
\text { Hematologic Disease } \\
\text { Infectious Disease } \\
\text { Inflammatory Disease } \\
\text { Nephrological Disease } \\
\text { Reproductive Health }\end{array}$ \\
\hline
\end{tabular}

This sector of devices and adapters provides remote and individualized access for patients, enhancing the quality of life for many individuals restricted by physical disability, geographic location, or access to communication with health care providers. Smartphones also equip providers in underserved, remote, or nomadic locations with portable, useful, and convenient technology to provide optimal care. ${ }^{27}$ The remote and continuous monitoring of vital signs, accomplished through the use of these smartphone devices, has been associated with an earlier recognition of patient deterioration and reduction of total time spent in hospitals, possibly reducing the number of adverse effects related to hospitalization, such as hospital acquired infections. ${ }^{2,28}$ Also used in inpatient settings, physicians at Mayo clinic placed tracking devices on patient's post-operative using a mobile device to monitor their activity; overall, they found that there was a significant relationship between the number of steps taken and a decrease in hospital length of stay and dismissal disposition. ${ }^{29}$ Therefore, these devices not only provide patients with the ability to self-monitor but they also augment the tools that physicians have to provide better care, whether in person or remotely.

\section{The impact of networks of information for tracking and reporting}

Medical applications can also be used as a part of a Personal Area Network (PAN) or Wireless Body Area Network (WBAN). These devices connect wirelessly and their applications are designed to collect, organize and interpret the information for the user, forming networks of information in the process. ${ }^{30}$ By using multiple inputs to integrate information and derive more accurate data, the information from multiple smartphones can be aggregated and used as study populations in addition to an individual. This is usually accomplished by using passive tracking, such as patient demographic data, amount of movement on an hourly basis, or geographical locations, in addition to active tracking like symptom reporting, to monitor social exchanges, community health, and disease spread. ${ }^{31-33}$ Social networks, in general, have been shown to affect the spread of obesity, smoking behavior and mental health. ${ }^{31,34-36}$ Eagle et al., ${ }^{33}$ performed a study showing that it was possible to use the physical locations of individuals and their calling patterns to accurately infer $95 \%$ of social network structures. These networks have since been studied in more depth and have successfully been able to predict the health status of individuals. ${ }^{31}$ In sum, the amount of information that is obtained from smartphones allows for a more in-depth analysis, not only of reported data, but of passive social exchanges, which may not only reveal patterns for an individual's behaviors but can be aggregated and leveraged to reveal patterns about populations. ${ }^{37}$ Smartphones can enable epidemiologists to have a better understanding of the spread of diseases and will allow them to implement interventions via access to previously unavailable information.

\section{Obstacles}

Although the increasing role of mHealth within healthcare seems to be inevitable, it continues to raise several unresolved issues. At the forefront of these concerns are data security, encryption, and information protection. ${ }^{1,27}$ National surveys have reported a small but real public concern regarding the confidentiality of their medical information using mobile devices. ${ }^{38}$ There is currently no standard process to ensure encrypted storage and transmission of data collected via this technology. Proper security of this information must be established for both the servers and networks involved in this process. Additionally, regulations on telephone companies and application 
companies regarding access to, transmission of, and collection of sensitive information via their networks and programs also pose security concerns.

In addition to the security of information, the accuracy and precision of these sensors are important to establish. Currently, the specificity and sensitivity of this new technology is still unclear. Formal testing and standardization is required to prove effectiveness that is equal to or better than the standard of care to justify widespread use in healthcare. The U.S. Food and Drug Administration is still deliberating on how to effectively, if at all, regulate many of the medical screening and diagnostic tools. ${ }^{27}$ The fast pace in the development of innovative devices make it difficult to create regulations that will capture the full extent of their utility while simultaneously having standards in place to ensure that smartphones and their devices will promote care rather than hinder it. The importance of clinical trials in this field, measuring the efficiency of the technology, in addition to the sensitivity and specificity of the devices and technology compared to current gold standards is imperative for further progression and promotion of the field in conjunction with patient safety.

Lastly, the projected economics of this technological sector of medicine is currently unclear leading to cost concerns. With the role of providing these devices and technologies currently unassigned between private insurance companies, public programs like Medicaid and Medicare, and independent hospital or clinic organizations, the expense of implementation is a source of apprehension. Additionally, while physicians have shown interest in incorporating this technology into their practices, a recent survey of the American Medical Association, across a variety of practices, show that nearly $60 \%$ of physicians are still considered "non-users" of these devices for clinical purposes, identifying two major barriers being lack of provision of these devices at their work place (44\%) and that they do not believe that the technology is suited to their needs $(26 \%) .{ }^{39}$ Therefore, although they will likely improve productivity due to a decrease in office visits, physicians are often not reimbursed for many related-services, such as the interpretation and monitoring of data gathered by remote devices; this uncertainty jeopardizes the potential adoption these innovations. ${ }^{27}$ Regardless of the answer to these many concerns, it remains apparent that the rapidly evolving infrastructure is in need of attention to address these concerns in these early stages of growth.

\section{The future of smartphones in mHealth}

As applications in healthcare drive the expansion of smartphone applications and devices, many companies are trying to either create unique devices or make existing devices more accurate and convenient. One of the main uses for smartphones is in the management of chronic diseases, many of which require patients to be on complex medication regimens, which are associated with non-compliance and medication errors. ${ }^{40}$ Smartphone cases are being developed that will store and passively track, with internal sensors, the user's medications, promoting medication adherence by syncing with mobile applications that provide medication information, customized alerts and text notifications ${ }^{41}$ Another budding aspect of this technology is its role in diagnosis, with applications expanding on diagnostic capabilities and detection of malaria, ${ }^{42}$ melanoma ${ }^{43}$ and hearing loss ${ }^{44}$ among others. As this technology grows in its ability to provide earlier detection of abnormal conditions, disease prevention, and physical rehabilitation, ${ }^{45-47}$ companies will continue to develop innovative means of applying software for health benefits, such as the development of shirts with electromyography and heart rate sensors for post-stroke patients expedite at home rehabilitation. ${ }^{47}$

These innovations are paving the way for individualized patient care. Patients not only have access to health information, but can better track, monitor, and report diseases, fluctuations in health, and symptoms. With the increasing acceptance of mHealth, patients have more electronic access to their providers and medical records, allowing them to input information from smartphones directly into their medical records and caregivers' hands. With patient engagement promoted through these means and a growth in the movement of quantified self through mobile health technology, there is no limit to the role mobile technology will have in the field of medicine. ${ }^{48}$ The abundance of information these devices obtain permits clinicians worldwide to provide more immediate and personalized care tailored to the user's specific patterns, needs, and preferences.

Smartphones can also increase productivity of clinicians. ${ }^{49}$ The amount of information provided by smartphones remote monitoring and health applications allows clinicians to make faster and more wellinformed decisions. A recent study on the impact of this technology in cost-effectiveness projects that there will be productivity gains of $\$ 305.1$ billion over the next 10 years in medicine with the adoption of mHealth. ${ }^{49}$ Furthermore, the efficiency of smartphones can help to reduce the egregious health care costs: remote monitoring alone has been estimated to save the United States approximately $\$ 197$ billion over the next 25 years. ${ }^{27}$

\section{Conclusion}

The Health Information Technology for Economic and Clinical Health (HITECH) Act has incentivized clinicians nationwide to integrate health information technology into their practices, ranging from electronic and personal health records, E-prescribing, health information exchange, analytics and decision support, patient support tools, and mobile health technologies..$^{39}$ The majority of physicians who have adopted this cite faster and more accurate billing for services, saved time by using E-prescribing and better communication and care coordination capabilities due to interoperability. ${ }^{39}$ It is only natural that with expansion of this technology will provide more devices and utilities of this technology in healthcare, thereby expanding the role of mobile applications and devices in healthcare.

As the Patient and Protection Affordable Care Act (PPACA) continue to be incorporated into our society, molding the practices of healthcare in the United States, the utility of telehealth continues to grow. Moreover, this legislation contains several advances for this field that directs the new Center for Medicare and Medicaid Innovation to explore cost-efficient models using wireless technology to provide a higher standard of healthcare. ${ }^{50}$ Smartphones serve as an ideal medium to empower individuals to engage in their own healthcare, serve as open-access points for health technology, and bridge the gap of resources for physicians that are working in underserved areas, where equipment and service is limited. The organization of mHealth with regards to smartphones is proving to be a valuable asset but it still lacks support and validation from the clinical community. More studies must be done examining the effectiveness of smartphones in the clinical setting to mitigate concerns from both the patients and clinicians. The growing industry of smartphones, the increasing consumer demand and the promise of several recent technological advancements in the field make smartphones the next frontier of medicine, and holds the promise of promoting health and wellness 
across the broad spectrum of patients worldwide, as well as the potential to shape the field of medicine for future generations.

\section{Acknowledgements}

None.

\section{Conflicts of interests}

Author declares that there are no conflicts of interest.

\section{References}

1. Wicks P, Stamford J, Grootenhuis MA, et al. Innovations in e-health Qual Life Res. 2014;23(1):195-203.

2. Weinstein RS, Lopez AM, Joseph BA, et al. Telemedicine, telehealth, and mobile health applications that work: opportunities and barriers. Am J Med. 2014;127(3):183-187.

3. Min YH, Lee JW, Shin YW, et al. Daily collection of self-reporting sleep disturbance data via a smartphone app in breast cancer patients receiving chemotherapy: a feasibility study. J Med Internet Res. 2014;16(5):135.

4. Research2Guidance. Mobile Health Market Report 2013-2017: The Commercialization of mHealth Applications. 2013.

5. Boulos MN, Brewer AC, Karimkhani C, et al. Mobile medical and health apps: state of the art, concerns, regulatory control and certification. Online J Public Health Inform. 2014;5(3):229.

6. Eagle N. Mobile Phones as Sensors for Social Research. Handbook of Emergent Technologies in Social Research. 2011.

7. Lyckholm L, Heddinger SP, Parker G, et al. A randomized, placebo controlled trial of oral zinc for chemotherapy-related taste and smell disorders. J Pain Palliat Care Pharmacother. 2012;26(2):111-114.

8. Boland P. The emerging role of cell phone technology in ambulatory care. $J$ Ambul Care Manage. 2007;30(2):126-133.

9. Burke LE, Styn MA, Sereika SM, et al. Using mHealth technology to enhance self-monitoring for weight loss: a randomized trial. Am J Prev Med. 2012;43(1):20-26.

10. Srigley JA, Furness CD, Baker GR, et al. Quantification of the Hawthorne effect in hand hygiene compliance monitoring using an electronic monitoring system: a retrospective cohort study. BMJ Qual Saf. 2014.

11. Baldwin LP, Low PH, Picton C, et al. The use of mobile devices for information sharing in a technology-supported model of care in A\&E. Int J Electron Healthc. 2007;3(1):90-106.

12. Beard KV, Greenfield S, Morote ES, et al. Mobile technology: lessons learned along the way. Nurse Educ. 2011;36(3):103-106.

13. Russell SJ, El Khatib FH, Sinha M, et al. Outpatient Glycemic Control with a Bionic Pancreas in Type 1 Diabetes. $N$ Engl $\mathrm{J} \mathrm{Med}$. 2014;371(4):313-325.

14. Munro D. Apple Gives Epic And Mayo Bear Hug With HealthKit. 2014.

15. Dolan B. Withings offers blood pressure monitor for iPhone. 2011.

16. Dolan B. iHealth to launch Bluetooth wrist-worn blood pressure monitor next. 2012

17. Comstock J. Glooko launches FDA-cleared Android app, cable. 2013.

18. Dolan B. Sanofi Aventis, Agamatrix to launch first medical iPhone peripheral? 2010.

19. Dolan B. AliveCor launches smartphone-enabled heart monitor, analysis services direct-to-consumer. 2014.
20. Stopczynski A, Stahlhut C, Larsen JE, et al. The smartphone brain scanner: a portable real-time neuroimaging system. PLoS One. 2014;9(2):86733.

21. Empson R. CellScope Nabs \$1M From Khosla Ventures To Turn Your Smartphone Into A Microscope. 2012.

22. David M, Alexandre J, Lingmin He, et al. Simple, Low-Cost Smartphone Adapter for Rapid, High Quality Ocular Anterior Segment Imaging: A Photo Diary. Journal MTM. 2014;3(1):2-8.

23. Dolan B. March launch for SkyLight's smartphone-microscope adapter. 2012

24. Pai A. Mobisante raises $\$ 4.2 \mathrm{M}$ for mobile-enabled ultrasound probes 2013.

25. McLeish T. URI engineering team improves lab-on-a-chip blood testing technology with smartphone app, hand-held biosensor. 2012.

26. Silbert S. Cue measures vitamin D and fertility, brings lab testing to your home. 2014.

27. West DM. How Mobile Devices are Transforming Healthcare. Brookings Institute. 2012.

28. Brown H, Terrence J, Vasquez P, Bates DW, et al. Continuous monitoring in an inpatient medical-surgical unit: a controlled clinical trial. Am J Med. 2014;127(3):226-232.

29. Cook DJ, Thompson JE, Prinsen SK, et al. Functional recovery in the elderly after major surgery: assessment of mobility recovery using wireless technology. Ann Thorac Surg. 2013;96(3):1057-1061.

30. Emil Jovanov, Aleksandar Milenkovic, Piet C de Groen. A wireless body area network of intelligent motion sensors for computer assisted physical rehabilitation. J Neuroengineering Rehabil. 2005;2(1):6.

31. Anmol M Manuel C, David L, Alex P. Social sensing for epidemiological behavior change. USA: Proceedings of the 12th ACM international conference on Ubiquitous computing, New York; 2010. pp. 291-300.

32. Ginsberg J, Mohebbi MH, Patel RS, et al. Detecting influenza epidemics using search engine query data. Nature. 2009;457(7232):1012-1014.

33. Eagle N, Pentland AS, Lazer D. Inferring friendship network structure by using mobile phone data. Proc Natl Acad Sci USA. 2009;106(36):1527415278

34. Barabasi AL. Network medicine-from obesity to the "diseasome". $N$ Engl J Med. 2007;357(4):404-407.

35. Christakis NA, JH Fowler. The spread of obesity in a large social network over 32 years. $N$ Engl J Med. 2007;357(4):370-379.

36. Fowler JH, Christakis NA. Dynamic spread of happiness in a large social network: longitudinal analysis over 20 years in the Framingham Heart Study. BMJ. 2008;337:2338.

37. Lazer D, Pentland A, Adamic L, et al. Social science. Computational social science. Science. 2009;323(5915):721-723.

38. Katz JE, Rice RE. Public views of mobile medical devices and services: a US national survey of consumer sentiments towards RFID healthcare technology. Int J Med Inform. 2009;78(2):104-114.

39. Greenspun H, Sheryl C, Stanley EL. Physician adoption of health information technology: Implications for medical practice leaders and business partners. Deloitte Center for Health Solutions. 2013;1-12.

40. Mira JJ, Navarro I, Botella F, et al. A Spanish pillbox app for elderly patients taking multiple medications: randomized controlled trial. $\mathrm{J} \mathrm{Med}$ Internet Res. 2014;16(4):99.

41. Hayakawa M, Uchimura Y, Omae K, et al. A smartphone-based medication self-management system with realtime medication monitoring. Appl Clin Inform. 2013;4(1):37-52. 
42. Stemple CC, Angus SV, Park TS, et al. Smartphone-based optofluidic lab-on-a-chip for detecting pathogens from blood. $J$ Lab Autom. 2014;19(1):35-41.

43. Vano Galvan S, Paoli J, Rios Buceta L, et al. Skin Self-examination Using Smartphone Photography to Improve the Early Diagnosis of Melanoma. Actas Dermosifiliogr. 2014.

44. Choi JM, Sohn J, Ku Y, et al. Phoneme-based self hearing assessment on a smartphone. IEEE J Biomed Health Inform. 2013;17(3):526-529.

45. Dicianno BE, Parmanto B, Fairman AD, et al. Perspectives on the Evolution of Mobile (mHealth) Technologies and Application to Rehabilitation. Phys Ther. 2014.

46. Kelly D, Caulfield B. An investigation into non-invasive physical activity recognition using smartphones. Conf Proc IEEE Eng Med Biol Soc. 2012; 3340-3343.
47. Farjadian AB, Sivak ML, Mavroidis C. SQUID: sensorized shirt with smartphone interface for exercise monitoring and home rehabilitation. IEEE Int Conf Rehabil Robot. 2013. 6650451.

48. Appelboom G, LoPresti M, Reginster JY, et al. The quantified patient: a patient participatory culture. Curr Med Res Opin. 2014;1-3.

49. Entner R. The Wireless Industry: The Essential Engine of US Economic Growth. Recon Analytics. 2012;1-43.

50. Choi BH, Kang HJ, Ho GC, et al. Development and Evaluation of the Innovative Smartphone Interface Bioelectrical Impedance Analyzer. $J$ Med Devices. 2013;7(2). 